\title{
"Fat-But-Active": Does Physical Activity Play a Significant Role in Metabolic Syndrome Risk among Children of Different BMI Categories?
}

Thayse Natacha Gomes ${ }^{1}$, Fernanda Karina dos Santos ${ }^{1,2}$, Daniel Santos ${ }^{1}$, Raquel Nichele Chaves ${ }^{3}$, Michele Souza ${ }^{1,2}$, Peter Todd Katzmarzyk and José Maia ${ }^{*}$

${ }^{1}$ CIFI2D, Kinanthropometry Lab, Faculty of Sport, University of Porto, Rua Dr Plácido Costa, 91, 4200-450, Porto, Portugal

${ }^{2}$ CAPES Foundation, Ministry of Education of Brazil, Brasília - DF, Brazil

${ }^{3}$ Federal University of Technology - Paraná (UTFPR), Campus Curitibat, Brazil

${ }^{4}$ Pennington Biomedical Research Center, 6400 Perkins Road, Baton Rouge, LA 70808-4124, USA

\begin{abstract}
Objective: Physical inactivity and adiposity have relevant roles in Metabolic Syndrome (MS) expression. Given the high prevalence of overweight/obesity and low levels of Physical Activity (PA) among Portuguese children, this study intends to explore the idea of "fat-but-active" by analysing differences in MS risk factors across four distinct $\mathrm{BMI}$ and PA groups.

Methods: The sample comprises 389 Portuguese children from both sexes, aged 9-11 years. BMI was computed from measurements of height and weight, and PA was assessed by an accelerometer for 7 days. Moderate-ToVigorous PA (MVPA) was used to classify children as active ( $\geq 60 \mathrm{~min} /$ day) or inactive ( $<60 \mathrm{~min} /$ day). Children were divided in four groups: normal weight and active, normal weight and inactive, overweight and active, overweight and inactive. A continuous MS score (zMS) was computed from measures of waist circumference, glucose, triglycerides, HDL-cholesterol and mean arterial blood pressure.

Results: There was a high prevalence of overweight (51.9\%) among children, and only $35.2 \%$ were physically active. In general, the overweight and inactive group had the worst metabolic profile, while the normal weight active group had the best. Except for glucose, differences $(p<0.05)$ were found in the metabolic indicators and for $z M S$ across groups, but they are mainly observed between BMI groups, but not between MVPA groups.

Conclusion: MVPA did not attenuate the MS risk factors in the overweight group, given that MS indicators do not differ in children of the same group when taking into account their MVPA levels. This is a significant result for public health, where strategies related to nutritional education as well as promoting PA should be used to reduce adiposity in children and decrease MS risk factors in this population.
\end{abstract}

Keywords: Physical activity; BMI; Weight categories; Metabolic risk; Children; Lifestyle; Portugal

\section{Introduction}

Although the Metabolic Syndrome (MS), defined as a cluster of three or more metabolic abnormalities such as abdominal obesity, high blood pressure, dyslipidemia and dysglycemia, is mostly an adult health hazard, there is evidence showing that it is also a health problem in the paediatric population [1,2]. The rise in MS prevalence in children parallels the worldwide increases in childhood obesity. For example, Saland [3] reported that in North America, Asia and Europe, the prevalence of MS in obese youth ranges from $18 \%$ to $50 \%$, but in normal weight youth the prevalence is $1 \%$ or less. Similarly, a recent review of MS prevalence in children from North America, Latin America, Europe, Asia, and Australasia (aged 2-19 years) reported that in the general population, values ranged from $1.2 \%$ to $22.6 \%$, with rates up to $60 \%$ in overweight/obese youth, revealing their increased metabolic risk [2]. As obesity and metabolic abnormalities track well from childhood and adolescence to adulthood, it is of foremost importance to reduce these risk factors as early in life as possible to minimize the incidence of cardiovascular diseases later in life $[4,5]$.

There is some evidence that physically active children have a better metabolic profile than the less active, suggesting an inverse association between physical activity and MS [6,7]. Higher physical activity levels are associated with greater insulin sensitivity and HDL-cholesterol, and lower levels of blood pressure, adiposity and triglycerides [8-11]. Moderate-To-Vigorous Physical Activity (MVPA) levels and patterns in all likelihood play an important role as a mediational path to a healthier body weight, thus attenuating the risk of developing MS in youth $[7,12]$. Furthermore, a recent review addressing the role of physical activity and cardiorespiratory fitness concluded that both are separately and independently associated with metabolic risk factors in children and adolescents [7]. In addition, Brambilla et al. [12] pointed out that physical activity influences metabolic risk factors within body weight categories, where normal weight subjects with low physical activity levels have higher metabolic risk than more active ones, and obese subjects with high levels of physical activity have a lower metabolic risk than those who are inactive.

The association between physical fitness and MS in children has been investigated, within the concept of "fat but fit", where the role of body fatness and fitness levels on metabolic risk profiles has been explored [13,14]; however, the results have not always been in the

*Corresponding author: José Maia, 1CIFI2D, Kinanthropometry Lab, Faculty of Sport, University of Porto, Rua Dr Plácido Costa, 91, 4200-450, Porto, Portugal, Tel: +351 220425248; Fax: +351 225500689; E-mail: jmaia@fade.up.pt

Received June 19, 2014; Accepted August 27, 2014; Published September 05, 2014

Citation: Gomes TN, dos Santos FK, Santos D, Chaves RN, Souza M, et al (2014) "Fat-But-Active": Does Physical Activity Play a Significant Role in Metabolic Syndrome Risk among Children of Different BMI Categories? J Diabetes Metab 5 421 doi:10.4172/2155-6156.1000421

Copyright: (c) 2014 Gomes TN, et al. This is an open-access article distributed under the terms of the Creative Commons Attribution License, which permits unrestricted use, distribution, and reproduction in any medium, provided the original author and source are credited. 
same direction. There is some evidence that high fitness attenuates the effects of fatness on cardiovascular risk [13]; on the other hand there is also evidence that fatness may attenuate the benefits of fitness on cardiovascular risk [15]. Regarding physical activity, even with its known role on reducing cardiovascular risk factors, there is no clear evidence if it can attenuate the effect of fatness on cardiovascular risk factors in youth $[11,12]$.

Given the high prevalence of overweight and obesity in Portuguese youth, as well as the moderate prevalence of MS and the low percentage of children and adolescents that achieve the MVPA guidelines, it seems relevant to explore the idea of "fat-but-active" by analysing differences in MS risk factors across distinct BMI and PA groups [16-23].

\section{Methods}

\section{Sample}

The sample is from an ancillary study of the International Study of Childhood Obesity, Lifestyle and the Environment (ISCOLE), a research project conducted in 12 countries from all major world regions [24]. The ISCOLE sample is a two-level random sample of children aged 9-11 years old, from 23 schools from the Northern region of Portugal. Children were from the 5 th grade and a sample of $\approx 30-40$ children was randomly selected from each school ( $50 \%$ for each gender). The ISCOLE study was approved by the physical education department, the school principal and the parental council, from each school, before starting data collection.

From the 777 5th grade Portuguese children aged 9-11 years old (mean age $10.0 \pm 0.23$ ) taking part in ISCOLE, an opportunistic sub-sample comprising 389 children (219 girls, 170 boys) accepted to participate in an ancillary study to understand the relationship between physical activity, overweight/obesity and MS. All parents or legal guardians provided written consent for their child to take part in the study. Data were collected from September 2011 to January 2013. The study protocol was approved by the University of Porto ethics committee, as well as by the schools' directorate councils.

\section{Anthropometry}

Height, weight, waist circumference and sitting height measures were taken according to standardized ISCOLE procedures [24]. Each child was measured twice and, when necessary, a third measurement was taken if the difference between the previous two was outside the permissible range for each measure and its replica $(0.5 \mathrm{~cm}$ for height, sitting height and waist circumference, and $0.5 \mathrm{~kg}$ for weight). The mean value of each measured variable was used for analysis.

Body Mass Index (BMI) was calculated using the standard formula [weight $(\mathrm{kg}) /$ height $(\mathrm{m})^{2}$ ], and subjects were classified in two groups [normal weight, and overweight (including obese)] according to the cut-off points from the World Health Organization (WHO), based on BMI $z$-scores (normal weight: $<+1 \mathrm{SD}$; overweight/obese: $\geq+1 \mathrm{SD}$ ) [25].

\section{Physical activity}

Actigraph GT3X+ accelerometers (ActiGraph, Pensacola, FL), attached on the right waist, were used to monitor physical activity. The devices were activated at midnight on the first day and data were recorded with sampling rate of $80 \mathrm{~Hz}$. Children were instructed to wear the accelerometer for at least 7 days (including two weekend days), 24 hours/day. The delivery, reception and information about accelerometer use were made personally.
Accelerometer information was divided into daytime activities and nocturnal sleep time using an automated algorithm [26,27]. Non-wear time during the awake period was defined as any sequence of at least 20 consecutive minutes of zero activity counts [26,27]. To be eligible for this analysis, children had to have at least 4 days (with at least one weekend day) with a minimum of 10 hours of wear time per day; all 389 children fulfilled this condition.

Although the accelerometer provides information related to different physical activity phenotypes, only MVPA was used in the present study. Mean MVPA, according to the cut points defined by Evenson et al. [28] from valid days, was used to classify children into two groups, according to World Health Organization recommendations [29]: active children (mean MVPA $\geq 60$ minutes) and inactive children (mean MVPA $<60$ minutes). In addition, the frequencies of days children meet the MVPA guidelines among valid days were computed. MVPA was defined as greater than 574 activity counts using 15 second epochs, which has been shown to classify children accurately into physical activity intensity categories $[28,30]$.

\section{Biological maturity}

An estimate of biological maturity was obtained using the maturity offset method [31]. Using information on sex, age, and individual physical growth (sitting height, stature and body weight) this method estimates in decimal years the time from peak height velocity (PHV). A positive maturity offset indicates the number of years a child is beyond PHV; a negative maturity offset indicates the number of years before PHV.

\section{Metabolic syndrome}

MS indicators included Waist Circumference (WC), Mean Arterial Blood Pressure (MAP), Fasting Glucose (GLU), Triglycerides (TRI), and High-Density Lipoprotein Cholesterol (HDL-C). Resting SBP and DBP were measured using a digital Omron sphygmomanometer (5 Series ${ }^{\mathrm{mm}}$ Upper Arm Blood Pressure Monitor - BP742, England) after subjects had been at rest for at least 10 minutes [32]. Three measurements were taken with a 3-minute interval between successive measurements, and the mean value was used. The Mean Arterial Pressure (MAP) was calculated as: $[(\mathrm{SBP}-\mathrm{DBP} / 3)+\mathrm{DBP}]$. Finger-stick blood samples were collected after 10-12 hours of fasting and GLU, TRI and HDL-C were analyzed with a LDX point of care analyser [33]. The blood collection was performed in a private room, by a trained technician, and blood analysis was done immediately at the same place of blood collection. All of these procedures (blood collection and blood analysis) took about 5-10 minutes.

A standardized MS score (zMS) was computed using MAP, WC, GLU, TRI, and HDL-C, as previously described [34]. Using a stepwise regression analysis, all MS indicators were adjusted for sex and biological maturity, and the maturity- and sex-standardized residuals (z-score) from each one were obtained. The zMS was derived by summing the continuously distributed MS indicators, with the HDL-zscore been previously multiplied by -1 (given the negative relationship between MS and HDL). A lower zMS is indicative of a better metabolic profile. Notwithstanding the many cut-points proposed to define MS in children, there is still no consensus regarding which indicators should be used and their respective values, varying from one criterion to another. This fact, in association with the relatively low prevalence of MS in general in youth justifies the use of the zMS. As pointed out by Eisenmann [34], this low relative prevalence would require large sample sizes for association studies, limiting the power to detect any 
relationship between exposure factors (such as physical activity, BMI) and a dichotomous outcome (having, or not, MS based on defined cutpoints). Further, several studies have used the zMS to represent the MS clustering components, with significant associations with physical activity $[6,35]$.

\section{Data Analysis}

Physical activity and BMI categories were used to determine the frequency of children classified in four groups (normal weight

\begin{tabular}{|c|c|c|}
\hline \multicolumn{2}{|l|}{ Variable } & $\begin{array}{c}\text { Means } \pm \text { sd or } \\
\text { Percentages (\%) }\end{array}$ \\
\hline \multicolumn{2}{|l|}{$\mathrm{BMI}\left(\mathrm{kg} / \mathrm{m}^{2}\right)$} & $19.7 \pm 3.3$ \\
\hline \multicolumn{2}{|l|}{ Maturity Offset (years relative to PHV) } & $-1.9 \pm 0.9$ \\
\hline \multicolumn{2}{|l|}{ MVPA (min/day) } & $55.5 \pm 21.4$ \\
\hline \multicolumn{2}{|l|}{ Average accelerometer valid days } & $6.8 \pm 0.6$ \\
\hline \multicolumn{2}{|l|}{ Average awake wear-time (min) } & $910.0 \pm 53.5$ \\
\hline \multicolumn{2}{|l|}{ Waist circumference $(\mathrm{cm})$} & $66.8 \pm 8.5$ \\
\hline \multicolumn{2}{|l|}{$\mathrm{HDL}(\mathrm{mg} / \mathrm{dl})$} & $52.5 \pm 13.0$ \\
\hline \multicolumn{2}{|l|}{ Triglycerides (mg/dl) } & $76.4 \pm 54.6$ \\
\hline \multicolumn{2}{|l|}{ Glucose $(\mathrm{mg} / \mathrm{dl})$} & $89.7 \pm 6.8$ \\
\hline \multicolumn{2}{|l|}{$\mathrm{SBP}(\mathrm{mmHg})$} & $107.3 \pm 10.4$ \\
\hline \multicolumn{2}{|l|}{$\mathrm{DBP}(\mathrm{mmHg})$} & $61.6 \pm 7.3$ \\
\hline \multicolumn{2}{|l|}{ MAP $(\mathrm{mmHg})$} & $76.8 \pm 7.4$ \\
\hline \multicolumn{2}{|l|}{ Metabolic Syndrome z Score } & $0.0 \pm 2.8$ \\
\hline \multicolumn{3}{|l|}{ BMI Classification (\%) } \\
\hline \multirow{2}{*}{ 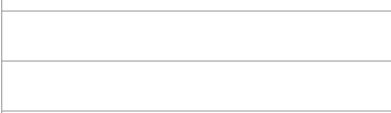 } & Normal weight & $48.1 \%$ \\
\hline & Overweight/Obese & $51.9 \%$ \\
\hline \multicolumn{3}{|l|}{ Physical Activity Level (mean/day) (\%) } \\
\hline \multirow{2}{*}{ (n) } & $\geq 60 \mathrm{~min}$ MVPA/day & $35.2 \%$ \\
\hline & $<60$ min MVPA/day & $64.8 \%$ \\
\hline \multicolumn{3}{|l|}{ Valid accelerometer days (\%) } \\
\hline \multirow{4}{*}{\begin{tabular}{|l|} 
\\
\\
\\
\end{tabular}} & 4 & $1.3 \%$ \\
\hline & 5 & $3.3 \%$ \\
\hline & 6 & $9.8 \%$ \\
\hline & 7 & $85.6 \%$ \\
\hline \multicolumn{3}{|l|}{ MVPA daily compliance (\%) } \\
\hline & No valid day & $18.5 \%$ \\
\hline & All valid days & $2.3 \%$ \\
\hline
\end{tabular}

Table 1: Descriptive statistics. and active; normal weight and inactive; overweight and active; and overweight and inactive). Weight status/physical activity groups' mean differences in each of the individual MS indicators, as well for zMS, were analysed with ANCOVA (Analysis of Covariance), controlling for sex and biological maturity. A Bonferroni adjusted multiplecomparison test was also used. All analyses were done in SPSS 20, and the significance level was set $\mathrm{p}<0.05$.

\section{Results}

Descriptive statistics are presented in Table 1 . The average accelerometer valid days was $\approx 7$; children had recorded about 910 minutes/day of waking wear time, and more than $95 \%$ of the sample had physical activity information for 6 or more days. On average, children's daily MVPA is 55.5 minutes, and only $35.2 \%$ of them reached the recommendations, considering the mean value. Taking into account the daily time spent in MVPA, only $2.3 \%$ of the sample achieved the WHO guidelines on all valid days, and $18.5 \%$ did not reach the guidelines on any day. More than half of the sample was classified as overweight or obese.

The frequency of children classified into the four groups was as follows: $17.2 \%$ in the normal weight and active group; $30.8 \%$ in the normal weight and inactive group; $18.0 \%$ in the overweight and active group; and $33.9 \%$ in the overweight and inactive group. Table 2 shows the ANCOVA results for individual risk factors, as well as the zMS, across the four BMI-physical activity groups. In general, the overweight and inactive group had the worst metabolic profile, while the normalweight and active group had the best. Except for glucose, statistically significant differences $(\mathrm{p}<0.05)$ were found for the metabolic indicators and for the zMS across groups. Further, a linear and significant trend was found for MS indicators (except for glucose) and zMS, across groups. In general, significant differences are mainly observed between BMI groups (normal weight versus overweight/obese), but not within groups (active versus inactive).

\section{Discussion}

It has been suggested that high levels of physical activity can attenuate the risk of MS in youth. We explored this idea across four distinct BMI and physical activity groups with Portuguese children aged 9-11 years, but firstly produced important descriptive epidemiology information. We showed that a high percentage of Portuguese 10year old children are overweight or obese, and also a high percentage does not reach the recommended levels of daily MVPA. These are apprehensive results, as the overweight prevalence differs somewhat from those found worldwide. For example, in a review of the

\begin{tabular}{|c|c|c|c|c|c|c|c|c|}
\hline \multirow[b]{2}{*}{ Variables } & \multicolumn{2}{|c|}{ Normal Weight } & \multicolumn{2}{|c|}{ Overweight } & \multirow[b]{2}{*}{$\mathbf{F}$} & \multirow[b]{2}{*}{$p$-value } & \multirow[b]{2}{*}{ Pairwise comparisons } & \multirow[b]{2}{*}{$\begin{array}{l}p \text {-value for } \\
\text { linear trend }\end{array}$} \\
\hline & $\begin{array}{l}\text { Active } \\
(n=67)\end{array}$ & $\begin{array}{l}\text { Inactive } \\
(n=120)\end{array}$ & $\begin{array}{l}\text { Active } \\
(n=70)\end{array}$ & $\begin{array}{l}\text { Inactive } \\
(n=132)\end{array}$ & & & & \\
\hline WC $(\mathrm{cm})$ & $62.0 \pm 0.6$ & $62.7 \pm 0.5$ & $70.3 \pm 0.6$ & $71.3 \pm 0.5$ & 75.11 & $<0.001$ & $\mathrm{NA}<\mathrm{OA} ; \mathrm{NA}<\mathrm{OI}$; $\mathrm{NI}<\mathrm{OA} ; \mathrm{NI}<\mathrm{OI}$ & $<0.001$ \\
\hline HDL (mg/dl) & $55.4 \pm 1.6$ & $54.5 \pm 1.2$ & $52.1 \pm 1.6$ & $49.4 \pm 1.1$ & 3.99 & 0.008 & $\mathrm{NA}>\mathrm{OI} ; \mathrm{NI}>\mathrm{OI}$ & 0.002 \\
\hline TRI (mg/dl) & $62.9 \pm 7.0$ & $67.1 \pm 5.3$ & $81.2 \pm 6.9$ & $89.2 \pm 4.9$ & 4.10 & 0.007 & $\mathrm{NA}<\mathrm{OI} ; \mathrm{NI}<\mathrm{OI}$ & 0.001 \\
\hline GLU (mg/dl) & $89.5 \pm 0.9$ & $89.5 \pm 0.7$ & $90.5 \pm 0.9$ & $89.6 \pm 0.6$ & 0.33 & 0.806 & ----- & 0.712 \\
\hline SBP $(\mathrm{mmHg})$ & $104.3 \pm 1.2$ & $106.0 \pm 0.9$ & $107.3 \pm 1.2$ & $110.0 \pm 0.8$ & 5.40 & 0.001 & $\mathrm{NA}<\mathrm{OI} ; \mathrm{NI}<\mathrm{OI}$ & $<0.001$ \\
\hline DBP $(\mathrm{mmHg})$ & $59.3 \pm 0.9$ & $61.3 \pm 0.7$ & $61.4 \pm 0.9$ & $63.1 \pm 0.7$ & 3.50 & 0.016 & $\mathrm{NA}<\mathrm{OI}$ & 0.003 \\
\hline MAP $(\mathrm{mmHg})$ & $74.3 \pm 0.9$ & $76.2 \pm 0.7$ & $76.7 \pm 0.9$ & $78.7 \pm 0.6$ & 5.44 & 0.001 & $\mathrm{NA}<\mathrm{OI} ; \mathrm{NI}<\mathrm{OI}$ & $<0.001$ \\
\hline ZMS & $-1.7 \pm 0.3$ & $-1.1 \pm 0.3$ & $0.8 \pm 0.3$ & $1.5 \pm 0.3$ & 26.55 & $<0.001$ & $\mathrm{NA}<\mathrm{OA} ; \mathrm{NA}<\mathrm{OI}$; $\mathrm{NI}<\mathrm{OA} ; \mathrm{NI}<\mathrm{OI}$ & $<0.001$ \\
\hline
\end{tabular}

WC: Waist circumference; TRI: Triglycerides; GLU: Glucose; SBP: Systolic blood pressure; DBP: Diastolic blood pressure; MAP: Mean arterial pressure; zMS: Metabolic syndrome z score; NA: Normal weight and physically active group; NI: Normal weight and inactive group; OA: Overweight and physically active group; OI: Overweight and inactive group

Table 2: Differences in metabolic risk indicators and zMS across BMI-physical activity groups, controlling for sex and biological maturity. 
overweight/obesity prevalence among Brazilian youth (aged between 2-19 years), a prevalence of overweight/obesity up to $28.2 \%$ was found [36], and Janssen et al. [37] reported prevalences higher than $15 \%$ in several countries. Previous Portuguese studies, using children aged 1011 years, reported that the prevalence of overweight and obesity ranged between $18.7 \%-30.4 \%$ and $5.8 \%-28.0 \%$, which is lower than what we reported in the present study, and these differences can be related to the use of different cut-points (WHO, CDC, IOTF), as well as differences in sample characteristics (since these two previous studies used samples from Portugal mainland, and in the present study the sample came from the Porto region) $[14,15]$.

In any case, these results highlight the actual overweight/obesity trends in paediatric populations, namely among Western and developed countries [37]. The main hypothesized reasons for these changes in obesity are related to changes in nutrition and physical activity habits observed in the last decades, which are influenced by social, environmental, interpersonal, community, governmental and biological characteristics, and that, are closely related to increases in metabolic risk factors in children and adolescents [38-40].

Although there is some disagreement concerning a physical activity decline across time or the presence of low physical activity levels among youth, our results are in line with those from Baptista et al. [23], where they show that $\approx 64 \%$ of Portuguese children aged $10-11$ years did not achieve the guidelines for daily MVPA [41,42]. Additionally, a recent review reported that about $80.3 \%$ of $13-15$ years-old worldwide do not reach the $60 \mathrm{~min} /$ day of MVPA [43]. This scenario (low levels of physical activity and high prevalence of children with overweight or obesity) are hypothesized to be the result of children's adverse lifestyles, mostly characterized by increases in sedentary activities and overconsumption of unhealthy, energy-dense food [44].

The main aim of the present study was to investigate if differences in MS risk factors could be linked to different BMI and physical activity groups: normal-weight and active; normal weight and inactive; overweight and active; overweight and inactive. As expected, the worst metabolic profile was found among the overweight and inactive group which makes them an important group to target for interventions, while the best metabolic profile was from the normal weight and active children, implying that children with high physical activity levels and low BMI are less prone to develop MS.

It has been suggested that physical activity and adiposity have relevant roles on the development of MS risk factors in children, but it is not clear if these traits act separately and independently or in conjunction $[45,46]$. Regarding physical activity, a recent review by Guinhouya et al. [47] reports that the impact of physical activity on MS appeared to be either independent of other factors, or mediated by adiposity in youth. There is some evidence that children with higher physical activity levels have a better metabolic risk profile than their peers with lower physical activity levels [6,7]. In this context, Ekelund et al. [9], concluded that physical activity is inversely associated with metabolic risk, independent of cardiorespiratory fitness and adiposity. According to the authors, this result has several implications for public health, since increasing overall physical activity, such as through play, active transport, and involvement in sport have beneficial effects on children's metabolic risk profile.

If on one hand, physical activity prevents the development of metabolic risk, it seems clear that adiposity acts in the opposite fashion, being a stronger predictor of metabolic risk in children than physical activity or even physical fitness [11,48]. Additionally, previous studies
[2,3] have also reported that among overweight/obese youth the prevalence of MS is higher than in normal weight youth, highlighting the adverse role of adiposity in the development of cardio-metabolic risk factors, namely MS.

Few studies have demonstrated that physical activity can attenuate the negative association between adiposity and metabolic risk, where high levels of physical activity improves the MS profile among obese subjects, increasing muscle mass and thus having a direct effect on metabolic function, changing cardiovascular risk factors $[12,49]$. However, in our study we did not find a significant physical activity effect on zMS, and no difference was observed within BMI groups (active versus inactive), meaning that physical activity does not attenuate the MS risk among normal weight children or even among those who are overweight. This result can be related to two distinct factors. Firstly, it can reinforce the notion that adiposity is more strongly correlated with MS risk factors than physical activity. The second possible explanation for this result can be mean value of 60 minutes of MVPA used to classify subjects as active and inactive, as this cut-point may not be sufficient for preventing the clustering of risk factors in children $[6,50]$.

Notwithstanding the importance of the present results, this study has several limitations that must be discussed. Firstly, although we have a somewhat small sample size and limitations in the number of cases in the four groups, we had enough power to detect differences [a posteriori power analysis showed that, with the exception of glucose (observed power $=0.24$ ) and DBP (observed power=0.62), the power was higher than 0.80 in all other variables]; It should be noted that available research linking MS and objectively measured physical activity have similar sample sizes as ours [51]. Secondly, the sample comes from one Portuguese region, and the results do not reflect all Portuguese children. Thirdly, this study has a cross-sectional design which does not allow for clearly determining if the role of PA in attenuating the BMI effects on MS risk changes over time. Despite the limitations, this investigation has several important strengths: first, the use of an objective method to estimate children's PA; secondly, the use of the accelerometer for a whole week; thirdly, the use of rigorous standard methods and trained personnel to collect high reliable data, and finally to explore the idea of "fat-but-active", cross-tabulating our sample into four groups according to BMI and physical activity levels.

\section{Conclusion}

In summary, MVPA did not attenuate the MS risk factors in overweight Portuguese children, given that MS indicators do not differ in children of the same weight group when taking into account their MVPA levels. On the other hand, weight category seems to be the important link to MS, since the metabolic profile found in the normal weight and active group was significantly better than the one found in overweight and active children. In our view this may represent a significant result in terms of public health to enhance interventions associated with nutritional education and consumption of healthy food which may help the reduction of children MS risk factors. Further, since sustained and systematic MVPA acts on weight control, namely through adiposity reduction, strategies to improve physical activity must also be considered.

\section{Acknowledgment}

We would like to thank Pedro Gil Silva, Sofia Cachada, Sara Oliveira and Alessandra Borges for their role in data collection for the Portuguese site of ISCOLE, and the Coordinating Center of ISCOLE in Baton Rouge, Louisiana. We would also like to thank the study participants along with their parents, teachers and school principals for their involvement in the study. 
Citation: Gomes TN, dos Santos FK, Santos D, Chaves RN, Souza M, et al. (2014) "Fat-But-Active": Does Physical Activity Play a Significant Role in Metabolic Syndrome Risk among Children of Different BMI Categories? J Diabetes Metab 5: 421 doi:10.4172/2155-6156.1000421

Page 5 of 6

\section{Financial support}

ISCOLE was funded by the Coca-Cola Company, but this ancillary study was not. The funder had no role in study design, data collection and analysis, decision to publish, or preparation of this manuscript.

\section{References}

1. Alberti KG, Zimmet P, Shaw J (2006) Metabolic syndrome--a new world-wide definition. A Consensus Statement from the International Diabetes Federation. Diabet Med 23: 469-480.

2. Tailor AM, Peeters PH, Norat T, Vineis P, Romaguera D (2010) An update on the prevalence of the metabolic syndrome in children and adolescents. Int J Pediatr Obes 5: 202-213.

3. Saland JM (2007) Update on the metabolic syndrome in children. Curr Opin Pediatr 19: 183-191.

4. Deshmukh-Taskar P, Nicklas TA, Morales M, Yang SJ, Zakeri I, et al. (2006) Tracking of overweight status from childhood to young adulthood: the Bogalusa Heart Study. Eur J Clin Nutr 60: 48-57.

5. Berenson GS, Srnivasan SR; Bogalusa Heart Study Group (2005) Cardiovascular risk factors in youth with implications for aging: the Bogalusa Heart Study. Neurobiol Aging 26: 303-307.

6. Andersen LB, Harro M, Sardinha LB, Froberg K, Ekelund U, et al. (2006) Physical activity and clustered cardiovascular risk in children: a cross-sectional study (The European Youth Heart Study). Lancet 368: 299-304.

7. Steele RM, Brage S, Corder K, Wareham NJ, Ekelund U (2008) Physical activity, cardiorespiratory fitness, and the metabolic syndrome in youth. J Appl Physiol (1985) 105: 342-351.

8. Park TG, Hong HR, Lee J, Kang HS (2007) Lifestyle plus exercise intervention improves metabolic syndrome markers without change in adiponectin in obese girls. Ann Nutr Metab 51: 197-203

9. Ekelund U, Anderssen SA, Froberg K, Sardinha LB, Andersen LB, et al. (2007) Independent associations of physical activity and cardiorespiratory fitness with metabolic risk factors in children: the European youth heart study. Diabetologia 50: $1832-1840$

10. Fulton JE, Dai S, Steffen LM, Grunbaum JA, Shah SM, et al. (2009) Physical activity, energy intake, sedentary behavior, and adiposity in youth. Am J Prev Med 37: S40-49.

11. Ekelund U, Brage S, Froberg K, Harro M, Anderssen SA, et al. (2006) TV viewing and physical activity are independently associated with metabolic risk in children: the European Youth Heart Study. PLoS Med 3: e488.

12. Brambilla P, Pozzobon G, Pietrobelli A (2011) Physical activity as the main therapeutic tool for metabolic syndrome in childhood. Int J Obes (Lond) 35 : 16-28.

13. Eisenmann JC, Welk GJ, Ihmels M, Dollman J (2007) Fatness, fitness, and cardiovascular disease risk factors in children and adolescents. Med Sci Sports Exerc 39: 1251-1256.

14. Eisenmann JC, Katzmarzyk PT, Perusse L, Tremblay A, Després JP, et al. (2005) Aerobic fitness, body mass index, and CVD risk factors among adolescents: the Québec family study. Int J Obes (Lond) 29: 1077-1083.

15. Moschonis G, Mougios V, Papandreou C, Lionis C, Chrousos GP, et al. (2013) "Leaner and less fit" children have a better cardiometabolic profile than their "heavier and more fit" peers: the Healthy Growth Study. Nutr Metab Cardiovasc Dis 23: 1058-1065.

16. Sardinha LB, Santos R, Vale S, Silva AM, Ferreira JP, et al. (2011) Prevalence of overweight and obesity among Portuguese youth: a study in a representative sample of 10-18-year-old children and adolescents. Int J Pediatr Obes 6: e124128.

17. Plataforma Contra a Obesidade (2009) Estudo de prevalência da obesidade infantil e dos adolescentes em Portugal Continental.

18. Seabra AF, Mendonça DM, Thomis MA, Anjos LA, Maia JA (2008) [Biological and socio-cultural determinants of physical activity in adolescents]. Cad Saude Publica 24: 721-736.

19. Maia J (2010) Santo Tirso comVida e com saúde. Porto.

20. Pedrosa C, Oliveira BM, Albuquerque I, Simoes-Pereira C, Vaz-de-Almeida $\mathrm{MD}$, et al. (2011) Markers of metabolic syndrome in obese children before and after 1-year lifestyle intervention program. Eur J Nutr 50: 391-400.

21. Braga-Tavares H, Fonseca $H$ (2010) Prevalence of metabolic syndrome in a Portuguese obese adolescent population according to three different definitions. Eur J Pediatr 169: 935-940.

22. Pedrosa C, Oliveira BM, Albuquerque I, Simões-Pereira C, Vaz-de-Almeida MD, et al. (2010) Obesity and metabolic syndrome in 7-9 years-old Portuguese schoolchildren. Diabetol Metab Syndr 2: 40.

23. Baptista F, Santos DA, Silva AM, Mota J, Santos R, et al. (2012) Prevalence of the Portuguese population attaining sufficient physical activity. Med Sci Sports Exerc 44: 466-473.

24. Katzmarzyk PT, Barreira TV, Broyles ST, Champagne CM, Chaput JP, et al. (2013) The International Study of Childhood Obesity, Lifestyle and the Environment (ISCOLE): design and methods. BMC Public Health 13: 900.

25. de Onis M, Onyango AW, Borghi E, Siyam A, Nishida C, et al. (2007) Development of a WHO growth reference for school-aged children and adolescents. Bull World Health Organ 85: 660-667.

26. Tudor-Locke C, Barreira TV, Schuna JM Jr, Mire EF, Katzmarzyk PT (2014) Fully automated waist-worn accelerometer algorithm for detecting children's sleep-period time separate from 24-h physical activity or sedentary behaviors. Appl Physiol Nutr Metab 39: 53-57.

27. Barreira TV, Schuna Jr JM, Mire EF, Katzmarzyk PT, Chaput J-P, et al. (In press) Identifying children's nocturnal sleep using 24-hour waist accelerometry. Med Sci Sports Exerc.

28. Evenson KR, Catellier DJ, Gill K, Ondrak KS, McMurray RG (2008) Calibration of two objective measures of physical activity for children. J Sports Sci 26 : 1557-1565.

29. World Health Organization (2010) Global recommendation on physical activity for health. Geneva: WHO Press.

30. Trost SG, Loprinzi PD, Moore R, Pfeiffer KA(2011) Comparison of accelerometer cut points for predicting activity intensity in youth. Med Sci Sports Exerc 43 1360-1368.

31. Mirwald RL, Baxter-Jones AD, Bailey DA, Beunen GP (2002) An assessment of maturity from anthropometric measurements. Med Sci Sports Exerc 34: 689694.

32. National High Blood Pressure Education Program Working Group on High Blood Pressure in Children and Adolescents (2004) The fourth report on the diagnosis, evaluation, and treatment of high blood pressure in children and adolescents. Pediatrics 114: 555-576.

33. LDX C (2003) The accuracy and reproducibility of a rapid, fingerstick method for measuring a complete lipid profile is comparable to a reference laboratory method (b): Cholestec Corporation.

34. Eisenmann JC (2008) On the use of a continuous metabolic syndrome score in pediatric research. Cardiovasc Diabetol 7: 17

35. Brage S, Wedderkopp N, Ekelund U, Franks PW, Wareham NJ, et al. (2004) Features of the metabolic syndrome are associated with objectively measured physical activity and fitness in Danish children: the European Youth Heart Study (EYHS). Diabetes Care 27: 2141-2148.

36. Tassitano R, Tenório M, Hallal P (2009) Revisão sistemática sobre obesidade em adolescentes brasileiros. Revista Brasileira de Cineantropometria Desempenho Humano 11: 449-456.

37. Janssen I, Katzmarzyk PT, Boyce WF, Vereecken C, Mulvihill C, et al. (2005) Comparison of overweight and obesity prevalence in school-aged youth from 34 countries and their relationships with physical activity and dietary patterns. Obes Rev 6: 123-132.

38. Huang TT, Glass TA (2008) Transforming research strategies for understanding and preventing obesity. JAMA 300: 1811-1813.

39. Cook S (2004) The metabolic syndrome: antecedent of adult cardiovascula disease in pediatrics. J Pediatr 145: 427-430.

40. Malina RM, Little BB (2008) Physical activity: the present in the context of the past. Am J Hum Biol 20: 373-391.

41. Knuth AG, Hallal PC (2009) Temporal trends in physical activity: a systematic review. J Phys Act Health 6: 548-559.

42. Ekelund U, Tomkinson G, Armstrong N (2011) What proportion of youth are 
Citation: Gomes TN, dos Santos FK, Santos D, Chaves RN, Souza M, et al. (2014) "Fat-But-Active": Does Physical Activity Play a Significant Role in Metabolic Syndrome Risk among Children of Different BMI Categories? J Diabetes Metab 5: 421 doi:10.4172/2155-6156.1000421

Page 6 of 6

physically active? Measurement issues, levels and recent time trends. $\mathrm{Br} J$ Sports Med 45: 859-865

43. Hallal PC, Andersen LB, Bull FC, Guthold R, Haskell W, et al. (2012) Global physical activity levels: surveillance progress, pitfalls, and prospects. Lancet 380: 247-257.

44. de Onis M, Blössner M, Borghi E (2010) Global prevalence and trends of overweight and obesity among preschool children. Am J Clin Nutr 92: 12571264.

45. Ruiz J, Ortega F (2009) Physical activity and cardiovascular disease risk factors in children and adolescents. Curr Cardio Risk Rep 3: 281-287.

46. Bridger T (2009) Childhood obesity and cardiovascular disease. Paediatr Child Health 14: 177-182.

47. Guinhouya BC, Samouda H, Zitouni D, Vilhelm C, Hubert H (2011) Evidence of the influence of physical activity on the metabolic syndrome and/or on insulin resistance in pediatric populations: a systematic review. Int J Pediatr Obes 6 : 361-388.

48. Eisenmann JC (2007) Aerobic fitness, fatness and the metabolic syndrome in children and adolescents. Acta Paediatr 96: 1723-1729.

49. Kang HS, Gutin B, Barbeau P, Owens S, Lemmon CR, et al. (2002) Physical training improves insulin resistance syndrome markers in obese adolescents. Med Sci Sports Exerc 34: 1920-1927.

50. Verona J, Gilligan LE, Giménez C, Verona MF, Lombardo SM, et al. (2013) Physical activity and cardiometabolic risk in male children and adolescents: the Balcarce study. Life Sci 93: 64-68.

51. dos Santos FK, Gomes TNQF, Santos D, Prista A, Maia JAR (2011) Associação entre atividade física, aptidão cardiorrespiratória e síndrome metabólica em crianças e adolescentes. Estado da arte. Revista Brasileira de Atividade Física e Saúde 16: 55-61. 